\title{
A Qualitative Exploration of Former College Student-Athletes' Wellness
}
Authors' contribution:
A) conception and design of the study
B) acquisition of data
C) analysis and interpretation of data
D) manuscript preparation
E) obtaining funding

\author{
Shane Warehime ${ }^{\mathrm{A}-\mathrm{D}}$, Danae Dinkel ${ }^{\mathrm{A}-\mathrm{D}}$, Abby Bjornsen- \\ Ramig $^{\mathrm{A}-\mathrm{D}}$, Ashley Blount ${ }^{\mathrm{A}-\mathrm{D}}$ \\ University of Nebraska at Omaha
}

ABSTRACT

College student-athletes (SAs) may experience difficulties while transitioning from college, which could reduce their overall wellness. However, it is essential to understand positive transition experiences and outcomes, as this can guide future research and intervention efforts. The purpose of this study was to explore the factors that led to higher levels of wellness in former SAs. Semi-structured interviews guided by the Indivisible Self Model were completed with former SAs $(n=12)$. Overall, participants displayed high levels of wellness - most prominently in terms of work and exercise. Many SAs perceived their current wellness was equal, if not better compared to when they were SAs. These results illustrate examples of successful transitions of former SAs, which can guide future research and interventions.

KEYWORDS $\quad$ sport retirement; indivisible self model

\section{Introduction}

College graduation is accompanied by a challenging transition into the real world, which like many other major life transitions, may be distressing and can affect individuals' wellness (Hart \& Swenty 2015). For student-athletes (SAs) who already display reduced levels of wellness (Watson \& Kissinger 2007), transitioning from college may be an especially treacherous time. Research is needed to better understand the aspects of wellness that are impacted during SA's transition out of sport.

One method for exploring SA's wellness is through the Indivisible Self Model (IS-WEL; Myers \& Sweeney 2004). The IS-WEL model defines wellness as “...a way of life oriented toward optimal health and well-being, in which body, mind, and spirit are integrated by the individual to live life more fully" (Witmer \& Sweeney 1998, p. 43). The primary construct of this model is referred to as Total Wellness, which is comprised of five second-order factors: creative self, coping self, social self, essential self, and physical self. Each secondorder factor contains a number of third-order factors. The creative self is comprised of thinking, emotions, control, work, and positive humor; the coping self is comprised of leisure, stress-management, self-worth, and realistic beliefs; the essential self is comprised of spirituality, gender identity, cultural identity, and self-care; the social self is comprised of friendship and love; and the physical self is comprised of exercise and nutrition. The IS-WEL Model is an ideal framework to view the wellness of SAs, as many of the issues described in the literature align with the second- and third-order factors. 
Related to the creative self, SAs transitioning from college and athletics may struggle with career development. The time demands of college athletics make it more challenging to complete internships, utilize on-campus career development resources, and to network with potential employers (Hook 2012; Linnemeyer \& Brown 2010; Murphy, Petitpas, \& Brewer 1996). Further, 56.6\% of SAs believe it is somewhat likely that they will play professionally, while only $2.6 \%$ actually do so (National Collegiate Athletic Association [NCAA] 2013). Therefore, approximately $54 \%$ of current SAs may not perceive it necessary to take advantage of career development opportunities during their college career, which may lead former SAs to lack necessary educational and vocational skills and show low career self-efficacy and career maturity (Murphy, Petitpas, \& Brewer 1996; Watson \& Kissinger 2007). These deficiencies are directly related to the third-order factors of thinking, control, and work.

In terms of the coping self and essential self, transitioning SAs may also struggle with identity loss. SAs tend to develop an unbalanced identity as an athlete (Brewer, Van Raalte, \& Linder 1993; Comeaux \& Harrison 2011; Watson \& Kissinger 2007). This is commonly known as athletic identity, or the degree to which one identifies as an athlete (Brewer et al. 1993). It is important to take note of athletic identity for transitioning SAs because a strong athletic identity at the time of retirement is associated with adjustment difficulties (Erpič, Wylleman, \& Zupančič 2004; Grove, Lavallee, \& Gordon 1997; Martin, Fogarty, \& Albion 2014), lack of post-collegiate planning (Dimoula, Torregrosa, Psychountaki 2013; Erpič et al. 2004), and increased psychological difficulties (Erpič et al. 2004; Grove et al. 1997). These issues are consistent with the third-order factors of self-worth (coping self), realistic beliefs (coping self), and cultural identity (essential self).

Transitioning SAs may also experience lower levels of wellness in second-order factor of the social self. Many of the primary relationships (e.g., teammates, coaches) decrease substantially after graduation, resulting in a dissipating support network at the completion of college athletics (Weigand, Cohen, \& Merenstein 2013). The strain resulting from lack of social support has been linked to lower levels of wellness (Dalgard \& Tambs 1995; Watson 2015). Thus, SAs transitioning from college may be especially susceptible to issues with the third-order factors of friendship and love.

Lastly, transitioning SAs may struggle with the physical self. For example, recent research found that former SAs are equally as inactive as their non-athlete counterparts following graduation (Sorenson, Romano, Azen, Schroeder, \& Salem 2015). This is troublesome because:

a) lack of physical activity has been linked to lower levels of health and wellness;

b) consistent physical activity is more important for health, such as preventing cardiovascular disease, than previous athleticism; and

c) loss in peak condition for former athletes can have adverse psychological and physical effects (Brill, Burkhalter, Kohl, Blair, \& Goodyear 1989; Center for Disease Control [CDC] 2015; Lui et al. 2008; Petibois, Cassaigne, Gin, \& Deleris 2004; Weigand et al. 2013).

Psychologically, in the six months following completion of an athletic career, retired elite athletes experience a reduction in perceived physical condition, physical self-worth, body attractiveness, sport competence, and global self-esteem (Stephan, Bilard, Ninot, \& Deligières 2003). Physically inactive former athletes develop the same, if not greater, risk of chronic disease than sedentary individuals who were not athletes (Petibois, Cassaigne, Gin, \& Deleris 2004; Witkowski \& Spangeburg 2008). For instance, Petibois et al. (2004) found that former endurance athletes who are now sedentary are at amplified risk of issues with triglyceride metabolism, blood lipid disorders, and body composition. Due to the aforementioned issues, it appears that recently transitioned SAs may be deficient in the third-order factor of exercise.

Previous research has examined the transitions of both collegiate and professional former athletes, however, this research has mainly been approached from a deficit perspective, with little focus on positive outcomes of athlete retirement (Knights, Sherry, \& Ruddock-Hudson 2015). Additionally, there appears to be a lack of research examining athletes who are currently transitioning or recently transitioned from college (Knights et al. 2015). A qualitative approach is needed to gain deeper understanding of positive outcomes and athletes who have just entered into the transition phase of retirement (Knights et al. 2015). Therefore, the aim of the current study was twofold: 
1. Explore the wellness of recently (i.e., within five years of sport) transitioned former SAs; and

2. Examine what factors led to high levels of wellness in former SAs.

\section{Methods}

\section{Participants}

Twelve former SAs $(M=23.9, S D=1.83)$ were interviewed at a Division 1 Midwestern public university with an enrollment of approximately 15,000. Participants were mostly female (58.3\%), non-Hispanic white (91.7\%), and were from the following sports: men's soccer $(n=2)$, women's softball $(n=1)$, men's basketball $(n=1)$, women's swimming and diving $(n=2)$, men's wrestling $(n=1)$, women's soccer $(n=1)$, women's cross country $(n=2)$, women's track and field $(n=1)$, and women's golf $(n=1)$.

Participants were first recruited from contact with the athletic department's Director of Student Development (DSD) and contact with coaches. Both the DSD and coaches provided contact information of former SAs in their databases. Former SAs that reside in the same city as the university where the research was conducted were targeted in recruitment. Potential participants were initially contacted via email and provided a short description of the study. If interested, former SAs responded to the email to schedule an interview. Snowball sampling was utilized by asking participants at the conclusion of their interview if they knew any former SAs that would be interested in participating. If so, participants provided researchers with the contact information (email address) of the potential participants. Researchers then sent these former SAs the recruitment email.

\section{Procedure}

The authors utilized a phenomenological qualitative methodology (Moustakas 1994) to provide an indepth understanding of the participants' overall wellness and factors associated with the transition from college that may help explain their outcome. The researchers developed an interview guide based on the Indivisible Self Model (IS-WEL; Myers \& Sweeney 2004) (Table 1) to assess the wellness of former SAs. The IS-WEL is a strengths-based, multidimensional view of holistic wellness used within existing college and university programming with the objective of increasing the wellness of student populations (Myers \& Sweeney 2004; Myers, Luecht, \& Sweeney 2004). The IS-WEL model accounts for an individual's strengths, recognizing that strengths in one area can help overcome weaknesses in other areas. This model has been validated across disciplines and diverse populations (Myers et al. 2004). Examples of interview questions can be found in Table 1.

Former SAs completed a brief demographic questionnaire and the aforementioned semi-structured interviews. Interviews lasted 30 - 75 minutes and took place in a confidential room. Participants were provided a short description of the study, the risks and benefits of participation, and their rights as an interviewee. Verbal assent was obtained by those agreeing to participate. Only research personnel and the interviewee were present for the interview. An Institutional Review Board at a Medical Center associated with the institution at which the study took place approved this study.

\section{Data Analysis}

Interviews were audio recorded and transcribed verbatim into a Microsoft Word document. Each participant was given a numeric code and any identifying information (e.g., name) was not included within the transcript. Transcriptions were then uploaded into QSR NVivo 10 (Burlington, MA 2010), a qualitative analysis software. Data were analyzed using the process of immersion/crystallization (Crabtree \& Miller 1999). Immersion involves researchers immersing themselves in the data by reading the data in detail (Crabtree \& Miller 1999). Crystallization involves a period a reflecting in which immersion is suspended in an effort to identify specific patterns and themes noticed in the immersion process (Crabtree \& Miller 1999). 
Table 1. The indivisible self model and example interview questions

\begin{tabular}{|c|c|c|}
\hline $\begin{array}{l}\text { Second-order } \\
\text { factors }\end{array}$ & $\begin{array}{l}\text { Third-order } \\
\text { factors }\end{array}$ & Example interview questions \\
\hline Creative & $\begin{array}{ll}\text { - } & \text { Thinking } \\
\text { - } & \text { Emotions } \\
\text { - } & \text { Control } \\
\text { - } & \text { Work } \\
\text { - } & \text { Positive } \\
& \text { Humor } \\
\end{array}$ & $\begin{array}{l}\text { 'Do you feel your work is } \\
\text { meaningful?' } \\
\text { 'How would you describe your } \\
\text { mood on most days?' }\end{array}$ \\
\hline Coping & $\begin{array}{ll}\text { - } & \text { Leisure } \\
\text { - } & \text { Stress } \\
& \text { Management } \\
\text { - } & \text { Self-Worth } \\
\text { - } & \text { Realistic } \\
& \text { Beliefs }\end{array}$ & $\begin{array}{l}\text { 'What do you like about } \\
\text { yourself?' } \\
\text { 'How do you spend your free } \\
\text { time?' } \\
\text { 'Describe how you handle } \\
\text { stress.' }\end{array}$ \\
\hline Social & $\begin{array}{ll}\text { - } & \text { Friendship } \\
\text { - } & \text { Love }\end{array}$ & $\begin{array}{l}\text { 'Are you satisfied with } \\
\text { [friendships and romantic } \\
\text { relationships] in your life?' }\end{array}$ \\
\hline Essential & $\begin{array}{ll}\text { - } & \text { Spirituality } \\
\text { - } & \text { Self-Care } \\
\text { - } & \text { Gender } \\
& \text { Identity } \\
\text { - } & \text { Cultural } \\
& \text { Identity } \\
\end{array}$ & $\begin{array}{l}\text { 'How would you describe your } \\
\text { wellness?' } \\
\text { 'Describe how you maintain } \\
\text { your wellness.' }\end{array}$ \\
\hline Physical & $\begin{array}{ll}\text { - } & \text { Exercise } \\
\text { - } & \text { Nutrition }\end{array}$ & $\begin{array}{l}\text { 'Describe your level of physical } \\
\text { activity.' } \\
\text { 'Describe your nutrition.' }\end{array}$ \\
\hline
\end{tabular}

Source: Own study

To begin the coding process, an outline of the codebook based on the IS-WEL's (Myers et al. 2004) factors of wellness was developed (i.e., creative self, coping self, physical self, social self, essential self). Initially, two trained coders read and independently coded two interviews. Next the coders met to review the codes and to revise the codebook where discrepancies occurred. The two coders then read and independently coded two additional interviews and met again to review the codes and to finalize the codebook. After this, researchers immersed themselves in the data by reading and independently coding all interviews. Then they met to achieve consensus on all codes and overall themes. To eliminate biases in coding and validate the data, peer debriefing was used (Lincoln \& Guba 1985). To accomplish this, two additional researchers, one trained in qualitative research and the other familiar with the IS-WEL model, reviewed the codes to ensure they accurately represented the coded content. The researchers validated the data through the use of thick description (Holloway 1997; Lincoln \& Guba 1985), where accurate and articulate quotes from individual participants were selected to represent key findings.

\section{Results}

Below are results from data analysis. Results were grouped into themes based on the IS-WEL model and factors (Myers et al. 2004). Quotes from individual participants represent the key findings within each theme.

\section{Current Position}

At the time of the interview, the majority of participants did not have full-time jobs $(n=8)$. Of those, most were enrolled in college, either as a graduate student or were finishing their undergraduate degree $(n=$ 6). Further, several participants still had some connection to organized athletics (e.g., high school, college, club) $(n=6)$, primarily as coaching staff $(n=5)$. 


\section{Creative Self}

The most frequent positive references were related to the factors of control, emotions, and work. In terms of control, most of the participants $(n=10)$ felt they had a good overall sense of control in their lives. Participants identified over twice as many aspects of their life they had control over $(n=22)$ compared to aspects they would like to have more control over $(n=9)$. For example, one participant stated the following:

"I feel like I have a strong sense of control in my life. As far as my daily routine, it's set and I decide what I want to do and when I want to do it, ya know... to an extent. Um, I also feel like I have good control over my decision making and my emotions... I'm not like, full of rage, ya know? If something upsets me at work, I have control over the situation."

When asked to describe their usual mood, all of the participants stated they maintain positive emotions. Most frequently, participants referenced feeling happy or being in a good mood $(n=10)$. One participant commented,

"Great. I would say my mood is really good on most days. Uh, I would say, I am a pretty positive person in general and so it takes a lot to get me down."

In terms of work, all of participants perceived their work to be meaningful $(n=12)$. When reflecting on their career goals in college, the majority of participants reported having a specific career in mind $(n=10)$, although half of the participants $(n=6)$ reported that their former career goal was different than their current career goal. Further, only two participants reported that their career goals in college were related to athletics. For example, one participant commented:

"Uh, career goals of being a professional soccer player... I thought I was going to be a professional athlete and make money to be physically active uh, and have fun, and pretty much just play for the whole day for work and get paid for it. And so, it's a lot different now. Having to work, it's a little different. I mean I enjoy my job but it's not the same as going and playing soccer for an hour long and getting paid for it so."

Additionally, although participants were not asked about career development activities (i.e., internship, job shadowing), many referenced completing one of these activities during college $(n=8)$.

\section{Coping Self}

Participants generally responded positively on all three of the factors related to the coping self. In terms of self-worth, all participants reported feeling satisfied with themselves since they left college, and most identified their own positive personal or mental attributes as the source of satisfaction $(n=11)$. For instance, one participant stated,

"I like that I am a happy person, just because I think that makes other people happy... I also like that I am a very detailed person. You know, a very organized person."

In terms of leisure, most of the participants mentioned being active in their leisure time $(n=9)$. Further, the majority of participants felt they had more free time now than as a SA and, consequently, are better-rounded $(n=9)$. For example, one participant stated the following:

"[Not being a SA] gives me a lot more time to where I can choose what I wanna do. Um, normally... well, my free time when I was a student-athlete was spent trying to cut weight. So working out/exercise. Ya know, and then just staying up on my studies. It gives me a lot more freedom to get back to my family. Um, hunt, do some of the other hobbies that I enjoy, apart from athletics."

Similarly, another participant responded:

"I don't think I really did much of those [leisure activities] when I was a student athlete. I, I mean other than laughing and I shot pool every once and a while but, that was pretty fun. Um, but for the most part I was just so busy here that I just didn't have time and when I was in junior college too, since I had to drive a half hour and then I was there all day then I drove a half hour back every single day. I left my house at 6:30 in the morning and I was getting home at 6:30 at night so not a whole lot of time to do very much so definitely changed a lot. I have more free time to do things that I enjoy." 
In terms of stress, most of the participants reported being able to relax and handle stress well $(n=9)$. For example, one participant stated,

"I think I'm pretty good at handling stress."

Additionally, all participants also identified a specific strategy they used to manage stress, several of which mentioned physical activity or a lesson learned from athletic participation as one of their strategies $(n=$ 9). One participant commented,

“Um, I run. I don't know. Like, that's like my outlet. Like, I feel like, when I'm really like stressed I just need to like go for a run. Cause' I feel like it clears your mind."

Likewise, another participant stated:

“And that's one thing that sports has taught me too is like when you're in a stressful situation you don't, you don't look at the whole picture of why you're in a stressful situation. You just need to look at that next minute or that next hour or the next play, instead of looking at the whole picture of what could happen."

\section{Essential Self}

Participants displayed high levels of wellness in two factors of the essential self: self-care and spirituality. In terms of self-care, most of the participants reported high levels of wellness $(n=10)$. For example, one participant stated:

"Mentally and physically I think I'm doing pretty well. I think, my wellness is very well. Um, yeah.

Mentally I feel great; mentally I think I'm healthy. And I know I'm healthy mentally, which is probably the most important thing. And then physically I'm healthy. I so over all my wellness is great."

Further, all participants identified a strategy they use to maintain wellness, with a majority reporting physical activity as a means of doing so $(n=8)$. Most of those that mentioned physical activity also identified other strategies to maintain wellness $(n=7)$. For instance, one participant mentioned the following:

"Yeah, so like I said before we ride bikes, we do fun runs, um, we work out, I work out with my boyfriend or sometimes we have a gym here I work out here, um, but I don't do it as consistently as I like. So yeah, lifting weights, running for fun, riding bikes I would say those are the, and yoga."

Similarly, another participant stated:

"Going to see people. Hanging out with my friends. Doing something that's not for me. Um, doing something that is for me. And making sure that all of those are working together. So, not one area is getting focused on more than the other."

Many participants reported that their wellness was different compared to when they were a SA $(n=10)$. More specifically, the majority of participants said their overall wellness was greater than or equal to when they were a SA but they were physically less fit $(n=8)$. For example, one participant commented,

"I was definitely in a lot better shape. Not that I'm in bad shape now or I think I'm really out of shape, or I'm unhealthy. It's just, a different form of a healthy me."

Similarly, another participant stated:

"I think it's a lot better now. I think when I was a student-athlete I was solely focused on getting by in school and being at, like, peak performance at all times that I think I let...I didn't necessarily let a lot of other relationships go, but I just chose to focus on those instead of seeing a bigger picture."

Another participant responded:

"I would say I was probably more physically fit in that aspect than I was now, but I would say that I'm probably in a better place like mentally now that I'm, now that I'm a little older and yeah."

In terms of spirituality, most participants were satisfied with their current religious practices $(n=11)$. For instance, one participant responded, 
"Yeah, I really like it. The, it's, like, I've got to know a lot of people there. Um, really nice people. So I'm really satisfied with that."

\section{Social Self}

Participants displayed high levels of wellness in both factors of the social self. All participants identified qualities of good friendships and romantic relationships. Over half of participants reported having a large number of friends $(n=7)$, while others reported having a few close friends $(n=3)$. Most participants reported being satisfied with their current relationships $(n=10)$. For instance, one participant responded:

“Very, very much so. I...I couldn't imagine my life any other way. I mean, I'm very, very happy with my wife. I'm very lucky there. And then, being able to keep the same relationships with the guys that I went to high school with, some of my best friends that I grew up with. And then the relationships with the guys that I really wasn't around for very long, ya know, the two years wrestling, but you bond some pretty strong bonds there. Uh, very, very happy where I'm at."

\section{Physical Self}

Participants displayed high levels of wellness in both factors of the physical self. Relevant to exercise, all participants reported regular participation in physical activity. For example, one participant stated, "Um, I still workout 4-5 times a week. Sometimes more if I have like a less of a week." However, most reported being less active than when they were an SA $(n=9)$, with time being the most common barrier $(n=6)$. One participant commented:

"Um, I definitely allow myself to workout less than I did as a student-athlete, and I also don't put myself as strenuous of activities as I did when I was a student-athlete. Um, but I think relatively speaking, that was demanded of you when you were a student-athlete, and now I don't have as high of demand, but I still push myself during my workouts, so."

In terms of nutrition, most participants reported good overall nutrition $(n=11)$. For instance, one participant responded:

"Nutrition is...healthy. I think I do a good job of balancing. Lots of fruit and some veggies. Not a lot of red meat. Um, I'm not saying I'm perfect. Nobody is perfect. Uh...um, but yeah. Lots of fruit, lots of veggies. Um, I try not to eat...I rarely eat like potato chips or French fries or soda, I don't drink soda. I think that's a big one. I'm not a huge sweets person. Um, lots of fish."

In most cases, participants reported that their nutrition had improved since they were a SA $(n=10)$. One participant stated:

"I actually feel like my nutrition has gotten better since I was a student athlete. When I was a student athlete I didn't care what I ate because I just probably burned so many calories at practice and weights that like if I had pizza rolls at night I wasn't gonna make me gain weight. During, I mean I always tried to have a well-balanced diet. Like, I always tried to have my fruits and vegetables and higher protein. But like if I had a donut that morning it didn't hurt me. Like, I knew it was going to affect me. Right now I'd say I have a better nutrition."

\section{Discussion}

For SAs, transitioning from college is an especially challenging process that may decrease wellness. Although previous findings in this area are inconsistent, most research has focused on negative outcomes associated with transitioning from sport (Knights et al. 2015). However, it is critical to understand positive outcomes associated with this transition, as this data can guide future efforts to improve the transition process for SAs. Results from this study illustrate positive transition experiences and outcomes of recently transitioned former SAs. The aims of this study were to: a) explore the wellness of recently graduated former SAs; b) examine what factors may lead to high levels of wellness in former SAs.

In terms of the first aim of this study, transitioned former SAs widely displayed high levels of overall, holistic wellness based on semi-structured interviews guided by the IS-WEL model. Specifically, participants displayed high levels in the IS-WEL's factors of the creative self, coping self, essential self, social self, and physical self. Although the present study included a small, non-representative sample, these findings contradict 
themajority of previous research suggesting former SAs struggle with career development, athletic identity, lack of social support, and lack of physical activity (Baillie \& Danish 1992; Grove et al. 1997; Kerr \& Dacyshyn 2000; McKenna \& Thomas 2007; Sorenson et al. 2015).

In terms of the second aim of this study, participants displayed factors associated with high levels of wellness in each of the IS-WEL's five factors of wellness. Within the creative self (i.e., work, control, emotions, thinking, positive humor), participants generally displayed high levels of wellness in the factor of work. Several participants also reported having specific career goals outside of athletics while in college $(n=$ 10), which suggests they maintained a realistic understanding of their athletic career along with a sufficient level of career maturity while in college. Many also believed that they had sufficient resources to attain their career goals, with eight participants making reference to completing career development activities (e.g., internships, job shadowing) while in college even though the interviewer did not explicitly inquire about this. Completing internships and utilizing other campus career services have been shown to increase career preparedness (Brown 2004; Petitpas, Danish, McKelvain, \& Murphy 1992; McKnight et al. 2009). Therefore, these results suggest it may be important for SAs to maintain a sufficient level of career maturity while in college and one way to accomplish this is by completing internships and utilizing campus career services to explore opportunities.

Interestingly, all participants perceived their current work to be meaningful even though they were at varying stages of their career (e.g., student, employed part-time, full-time). These findings suggest that the participants in this study may have an optimistic disposition leading them to generally perceive their situation as favorable. Participants also displayed high levels of wellness in the emotions factor of the creative self, as most of the participants referenced regularly feeling happy or being in a good $\operatorname{mood}(n=10)$. According to Brissette, Scheier, and Carver (2002), greater optimism is associated with better adjustment during stressful life events, including transitional phases. Thus, these results illustrate the importance of positive emotions throughout SA's transition from athletics. One possible way of accomplishing this is by including positive imagery activities to an intervention aimed at less optimistic SAs. Positive imagery has been shown to increase future positive expectancies and decrease negative future expectancies (Meevissen, Peters, \& Alberts 2011).

Along with the creative self, participants also displayed high levels of wellness in the coping self (i.e., leisure, stress-management, self-worth, realistic beliefs) and essential self (i.e., spirituality, gender identity, cultural identity, and self-care). When asked how their view of themselves had changed since college, most participants described improving and/or maintaining positive qualities since college $(n=11)$. Additionally, only two of the participants indicated that their career goals in college involved athletics. Consequently, all of the participants reported being satisfied with their current self - illustrating the importance of SAs having the ability to develop positive self-qualities besides athleticism. This further supports the importance of optimism and developing a well-rounded identity in SAs in order to mitigate difficulties while transitioning (Brewer, Van Raalte, \& Linder 1993; Brissette, Scheier, \& Carver 2002)

In terms of the social self (i.e., friendship, love), participants generally displayed high levels of wellness. Specifically, the majority of participants were satisfied with their current relationships $(n=10)$. A strong sense of social support is associated with lower levels of mental illness, higher life quality, and, consequently, high levels of overall wellness (Armstrong \& Oomen-Early 2009; Watson \& Kissinger 2007). These findings suggest it is imperative for SAs to have a strong sense of social support that will not dissipate as they transition from college. It is important to note that participants were not asked to identify where they originally met their friends, thus it is unknown whether their current relationships were with former teammates or friends outside of athletics. Regardless, participants in this study were able to maintain a strong social network as they transitioned from athletics. This could be due to participants residing in the same city in which they went to college and it is possible that they were able to maintain relationships with other alumni that remained in the area. More research is needed on how to improve transitioning SAs' social support, especially on subpopulations who are more likely to lack support, such as first-generation college SAs (Pascarella, Pierson, Wolniak, \& Terenzini 2004; Terenzini, Springer, Yaegaer, Pascarella, \& Nora 1996). 
Participants also displayed high levels of wellness in the physical self(i.e., exercise, nutrition), especially exercise. All of the participants reported regular participation in physical activity. This contradicts recent research that found former SAs are equally as inactive as their non-athlete counterpart (Reifsteck, Gill, \& Brooks 2013; Sorenson et al. 2015). Participants also mentioned physical activity in other portions of the interview. When asked about managing stress, over half of participants mentioned utilizing physical activity as a means of means of doing so $(n=7)$. When discussing self-care, the majority of participants mentioned physical activity as a way they maintain wellness. Participation in regular physical activity has been linked to a multitude of physical and psychological benefits (Miller \& Hoffman 2009; Penedo \& Dahn 2005) and may be especially critical for SAs (Stephan, Bilard, Ninot, \& Deligières 2003; Wikowski \& Spangeburg 2008). Therefore, these results illustrate the importance of SAs understanding the benefits of PA and finding ways to continue participation post-collegiately to maintain or improve overall wellness.

\section{Limitations}

The present study is not without limitations. First, results cannot be generalized due to the qualitative nature of the sample. The sample was further homogenized by utilizing snowball sampling. Along with this, there may have been issues related to the gender distribution of the sample. Previous research indicates that female SAs may be less susceptible to issues with athletic transition due to the lack of professional athletic opportunities (Harrison \& Lawrence 2004). Therefore, because over half of the participants were female (58.3\%), these findings may not be representative of the entire SA population. Second, participants may have provided inaccurate information because of the self-report nature of the interview questions due to recall bias. Additionally, several questions required participants to discuss personal experiences, and due to social desirability, participants may have answered in ways that they perceive to be 'correct', rather than what is truthful.

The aforementioned limitations were addressed and minimized in various ways. The researchers purposefully selected a small sample to gather thorough, in-depth data in an effort to deepen understanding on this topic. To diversify the sample, former SAs from several sports were recruited. The twelve subjects in this study represented nine different sports - six women's sports, three men's sports. To gather accurate, personal data, subjects were ensured confidentiality and allowed to discontinue participation if they felt uncomfortable.

\section{Research Implications}

Based on these findings, there are a number of future research recommendations. In general, future efforts should continue to examine positive experiences and outcomes of transitioning SAs. These efforts could include a more diverse sample to increase understanding of the mechanisms of a SA's positive transition from athletics while controlling for recall bias and social desirability. Future efforts could also narrow in scope. It is essential to understand how different types of athletes handle transitioning from athletics. To address this, research could examine gender (e.g., male vs. female), specific sports and sport-types (e.g., revenue generating, team vs. individual), subpopulations (e.g., ethnic minorities, first-generation college students), and institution characteristics (e.g., Division I vs. II vs. III, private vs. public). Future research efforts could also aim to prevent issues in SAs transitioning from athletics. To do this, positive findings, such as those provided by this study, and research in other areas could be applied to develop and test interventions. Lastly, since this study displayed a cross-section of recently transitioned SAs, future studies could longitudinally examine if/how SAs' wellness varies throughout the transitional process.

\section{Practical Implications}

The present study has implications across various disciplines, including, but not limited to, academics, college-sport practitioners, and the general public. Specifically, this information could be used to develop or improve a transition assistance program for SAs. Based on the college experiences of many of the participants in this study, it appears essential for SAs to have opportunities to develop outside of athletics, as this can mitigate many of the issues SAs face while transitioning from college. For example, SAs can increase career preparedness by utilizing career development opportunities, develop a more well-rounded identity by pursuing 
other activities and interests, broaden social circles through exposure with non-athlete peers, and develop other physical activity interests by experimenting with other types of physical activity.

The findings of this study surrounding the wellness factors of work and exercise are most prominent and readily applicable to improving the wellness of transitioning SAs. In terms of work, findings from this study illustrate the importance of transitioning SAs' career preparedness. Thus, college sport practitioners, such as student-affair professionals within athletics, could encourage SAs to complete career development activities. To do so, the time demands of college athletics have to be accounted for. Unique career development opportunities that are compatible with athletic schedules could be created to increase accessibility for SAs. For example, since former SAs understand the rigors of college athletics, developing internship and job shadowing opportunities that connect current SAs to alumni SAs may be useful. Alumni SAs may be more willing to be flexible with SA's collegiate schedules, as well as provide an opportunity for SAs to see how other athletes have successfully transitioned from sport. In some cases career development opportunities may already be available for SAs. For instance, half of participants $(n=6)$ mentioned connections within the university's athletic department when discussing resources to attain their career goals and career development activities. Efforts to increase utilization of these opportunities may be more appropriate in these situations, such as annual career development workshops with SAs to get them accustomed to these opportunities and allow them to network with potential employers.

In terms of the wellness factor of exercise, findings from this study suggest that regular participation in physical activity is critical to the overall wellness of former SAs. Participants in this study participated in regular physical activity and understood many of the physical and psychological benefits of doing so. Participants also used physical activity to manage stress and improve and/or maintain wellness. However, the sample is likely not representative of all former SA, as research indicates former SAs are equally as inactive as their non-athlete counterparts (Reifsteck, Gill, \& Brooks 2013; Sorenson et al. 2015). Therefore, it is important for college sport practitioners to educate and encourage SAs to participate in physical activity postcollegiately. To do so, SAs may need time and opportunities outside of organized sport to explore other modes of physical activity that are more likely to be maintained long-term. For example, a former SA in this study developed an interest in CrossFit through their training regimen in college and, consequently, continued participation post-collegiately. Increasing situations such as this may be one way to help SAs develop physical activity interests and habits.

\section{Conclusions}

In sum, contrary to what previous researchers suggest, the former SAs that participated in this study displayed high levels of wellness. Specifically, previous researchers indicate former SAs may display lower levels of wellness as a result of struggling with career development, loss of identity, lack of social support, and reduced physical activity. However, the participants in the present study generally displayed high levels of wellness in all of these areas and, consequently, their responses may help guide researchers and future SAs in improving transition experiences and outcomes.

\section{REFERENCES}

Armstrong, S. \& Oomen-Early, J. (2009). Social connectedness, self-esteem, and depression symptomology among collegiate athletes versus non-athletes. Journal of American College Health, 57(5), 521-526.

Baillie, P.H., \& Danish, S.J. (1992). Understanding the career transition of athletes. The Sport Psychologist, 6(1), 77-98. Brewer, B.W., Van Raalte, J.L., \& Linder, D.E. (1993). Athletic identity: Hercules' muscles or Achilles heel?. International Journal of Sport Psychology, 24(2), 237-254. Retrieved from http://psycnet.apa.org/psycinfo/1994$\underline{03969-001}$

Brill, P.A., Burkhalter, H.E., Kohl, H.W., Blair, S.N, \& Goodyear, N.N. (1989). The impact of previous athleticism on exercise habits, physical fitness, and coronary heart disease risk factors in middle-aged men. Research Quarterly for Exercise and Sport, 60(3), 209-215.

Brissette, I., Scheier, M.F., \& Carver, C.S. (2002). The role of optimism in social network development, coping, and psychological adjustment during a life transition. Journal of Personality and Social Psychology, 82(1), 102-111. 
Brown, S.C. (2004). Where this path may lead: Understanding career decision-making for post-college life. Journal of College Student Development, 45(4), 375-390.

Center for Disease Control. (2015). Physical Activity and Health. Retrieved from https://www.cdc.gov/physicalactivity/basics/pa-health/

Comeaux, E., \& Harrison, C.K. (2011). A conceptual model of academic success for student-athletes. Educational Researcher, 40(5), 235-245.

Crabtree, B.F., \& Miller, W.L. (Eds.). (1999). Doing qualitative research. Thousand Oaks, CA: Sage Publications.

Dalgard, O.S., \& Tambs, K. (1995). Social support, negative life events and mental health. The British Journal of Psychiatry, 166(1), 29-34.

Dimoula, F., Torregrosa, M., Psychountaki, M., \& Fernandez, M.D.G. (2013). Retiring from elite sports in Greece and Spain. The Spanish Journal of Psychology, 16, E38.

Erpič, S.C., Wylleman, P., \& Zupančič, M. (2004). The effect of athletic and non-athletic factors on the sports career termination process. Psychology of Sport and Exercise, 5(1), 45-59.

Grove, J.R., Lavallee, D., \& Gordon, S. (1997). Coping with retirement from sport: The influence of athletic identity. Journal of Applied Sport Psychology, 9(2), 191-203.

Harrison, C.K., \& Lawrence, S.M. (2004). Female and male student athletes' perceptions of career transition in sport and higher education: A visual elicitation and qualitative assessment. Journal of Vocational Educational and Training, 56(4), 485-506.

Hart, J.A., \& Swenty, C.F. (2015). Understanding transitions to promote student success: A concept analysis. Nursing Forum. DOI:10.1111/nuf.12136

Holloway, I. (1997). Basic concepts for qualitative research. Hoboken, NJ: Wiley-Blackwell.

Hook, L.L. (2012). Athletic identity, vocational identity, and occupational engagement in college student-athletes and non-athletes. (Unpublished doctoral dissertation). University of Kansas, Lawrence, KS.

Kerr, G., \& Dacyshyn, A. (2000). The retirement experiences of elite, female gymnasts. Journal of Applied Sport Psychology, 12(2), 115-133.

Knights, S., Sherry, E., \& Ruddock-Hudson, M. (2015). Investigating elite end-of-athletic-career transition: a systematic review. Journal of Applied Sport Psychology, 28(3), 291-308.

Lincoln, Y.S., \& Guba, E.G. (1985). Naturalistic inquiry (Vol. 75). Thousand Oaks, CA: Sage Publications.

Linnemeyer, R.M., \& Brown, C. (2010). Career maturity and foreclosure in student athletes, fine arts students, and general college students. Journal of Career Development, 37(3), 616-634.

Liu, T.C., Liu, Y.Y., Lee, S.D., Huang, C.Y., Chien, K.Y., Cheng, I.S., et al. (2008). Effects of short-term detraining on measures of obesity and glucose tolerance in elite athletes. Journal of Sports Sciences, 26(9), 919-925.

Martin, L.A., Fogarty, G.J., \& Albion, M.J. (2014). Changes in athletic identity and life satisfaction of elite athletes as a function of retirement status. Journal of Applied Sport Psychology, 26(1), 96-110.

Meevissen, Y.M., Peters, M.L., \& Alberts, H.J. (2011). Becoming more optimistic by imaging a best possible self: Effects of a two week intervention. Journal of Behavior Therapy and Experimental Psychiatry, 42(3), 371-378.

McKenna, J., \& Thomas, H. (2007). Enduring injustice: A case study of retirement from professional rugby union. Sport, Education and Society, 12(1), 19-35.

McKnight, K., Bernes, K., Gunn, T., Chorney, D., Orr, D., \& Bardick, A. (2009). Life after sport: Athletic career transition and transferable skills. Journal of Excellence, 13, 63-77.

Miller, K.E., \& Hoffman, J.H. (2009). Mental well-being and sport-related identities in college students. Sociology of Sport Journal, 26(2), 335-356.

Moustakas, C. (1994). Phenomenological research methods. Thousand Oaks, CA: Sage Publications.

Murphy, G.M., Petitpas, A.J., \& Brewer, B.W. (1996). Identity foreclosure, athletic identity, and career maturity in intercollegiate athletes. Sport Psychologist, 10, 239-246.

Myers, J.E., Luecht, R.M., \& Sweeney, T.J. (2004). The factor structure of wellness: Reexamining theoretical and empirical models underlying the Wellness Evaluation of Lifestyle (WEL) and the Five-Factor Wel. Measurement and Evaluation in Counseling and Development, 36(4), 194-208.

Myers, J.E., \& Sweeney, T.J. (2004). The indivisible self: An evidence based model of wellness. Journal of Individual Psychology, 60(3), 234-245.

National Collegiate Athletic Association. (2013). So, you're telling me there's a chance. Indianapolis, IN. Retrieved from http://www.ncaa.org/about/resources/research/so-you-re-telling-me-there-s-chance 
Pascarella, E.T., Pierson, C.T., Wolniak, G.C., \& Terenzini, P.T. (2004). First-generation college students: Additional evidence on college experiences and outcomes. Journal of Higher Education, 75(3), 249-284.

Penedo, F.J., \& Dahn, J.R. (2005). Exercise and well-being: a review of mental and physical health benefits associated with physical activity. Current Opinion in Psychiatry, 18(2), 189-193.

Petibois, C., Cassaigne, A., Gin, H., \& Déléris, G. (2004). Lipid profile disorders induced by long-term cessation of physical activity in previously highly endurance-trained subjects. The Journal of Clinical Endocrinology \& Metabolism, 89(7), 3377-3384.

Petitpas, A., Danish, S., McKelvain, R., \& Murphy, S. (1992). A career assistance program for elite athletes. Journal of Counseling and Development, 70(3), 383-386.

Reifsteck, E.J., Gill, D.L., \& Brooks, D.L. (2013). The relationship between athletic identity and physical activity among former college athletes. Athletic Insight, 5(3), 271-284.

Sorenson, S.C., Romano, R., Azen, S.P., Schroeder, E.T., \& Salem, G.J. (2015). Life span exercise among elite intercollegiate student athletes. Sports Health: A Multidisciplinary Approach, 7(1), 80-86.

Stephan, Y., Bilard, J., Ninot, G., \& Delignières, D. (2003). Bodily transition out of elite sport: A one-year study of physical self and global self-esteem among transitional athletes. International Journal of Sport and Exercise Psychology, 1(2), 192-207.

Terenzini, P.T., Springer, L., Yaeger, P.M., Pascarella, E.T., \& Nora, A. (1996). First-generation college students: Characteristics, experiences, and cognitive development. Research in Higher Education, 37(1), 1-22.

Watson, J.C. (2015). A holistic wellness approach toward counseling college athletes. In E. Comeaux (Ed). Making the connection: Data-informed practices in academic support centers for college athletes (pp. 33-46). Charlotte, NC: Information Age Publishing.

Watson, J.C. \& Kissinger, D.B. (2007). Athletic participation and wellness: Implications for counseling college studentathletes. Journal of College Counseling, 10(2), 153-162.

Weigand, S., Cohen, J., \& Merenstein, D. (2013). Susceptibility for depression in current and retired student athletes. Sports Health: A Multidisciplinary Approach, 5(3), 263-266.

Witkowski, S., \& Spangenburg, E.E. (2008). Reduced physical activity and the retired athlete: a dangerous combination?. British Journal of Sports Medicine, 42(12), 952-953.

Witmer, J.M., \& Sweeney, T.J. (1998). Toward wellness: The goal of counseling. In T.J. Sweeney (Ed.), Adlerian counseling: A practitioner's approach (p. 43). Philadelphia, PA: Accelerated Development, Taylor \& Francis Group.

AUTHOR'S ADDRESS: Shane Warehime

University of Nebraska at Omaha

6001 Dodge St., H \& K 207GG

Omaha, NE 68182

USA

E-mail: swarehime@unomaha.edu

Received: 3 May 2017; Accepted: 26 June 2017 